\title{
Doping of amorphous and microcrystalline silicon films deposited at low substrate temperatures by hot- wire chemical vapor deposition
}

\author{
P. Alpuim, V. Chu \\ Instituto de Engenharia de Sistemas e Computadores (INESC), \\ Rua Alves Redol, 9, 1000-029 Lisboa, Portugal \\ J. P. Conde \\ Department of Materials Engineering, Instituto Superior Técnico, \\ 1049-001 Lisboa, Portugal
}

PACS: $\quad$ 73.61.Tm, 81.05.Ys, 81.05Gc, 71.55Jc, 61.43.Dq 


\section{ABSTRACT}

The gas phase doping of amorphous (a-Si:H) and microcrystalline ( $\mu \mathrm{c}-\mathrm{Si}: \mathrm{H})$ silicon thin films deposited at substrate temperatures of $25^{\circ} \mathrm{C}$ and $100^{\circ} \mathrm{C}$ by hot-wire chemical vapor deposition is studied. Phosphine was used for $\mathrm{n}$-type doping and diborane for $\mathrm{p}$ type doping. The electronic and structural properties of the doped films are studied as functions of hydrogen dilution. Films were deposited on glass and polyethylene terephthalate. Similar dark conductivities, $\sigma_{d}$, were obtained for the doped films deposited on either substrate. $\sigma_{\mathrm{d}}$ above $10^{-6} \Omega^{-1} \mathrm{~cm}^{-1}$ were obtained for a-Si:H films doped n-type at $25^{\circ} \mathrm{C}$ and $100^{\circ} \mathrm{C}\left(\sigma_{\mathrm{d}}>10^{-4} \Omega^{-1} \mathrm{~cm}^{-1}\right)$ and for a-Si:H doped p-type only at $100^{\circ} \mathrm{C} . \sigma_{\mathrm{d}}$ equal or above $10^{-1} \Omega^{-1} \mathrm{~cm}^{-1}$ were obtained for $\mu \mathrm{c}-\mathrm{Si}: \mathrm{H}$ doped p-type at $25^{\circ} \mathrm{C}$ and $100^{\circ} \mathrm{C}$ and for $\mu \mathrm{c}-\mathrm{Si}: \mathrm{H}$ doped n-type only at $100^{\circ} \mathrm{C}$. Isochronal annealing at temperatures up to $200^{\circ} \mathrm{C}$ reveals that, while the dopants are fully activated in microcrystalline samples, they are only partially activated in amorphous films deposited at low substrate temperature. 


\section{INTRODUCTION}

There has recently been great interest in the deposition of hydrogenated amorphous (a-Si:H) and microcrystalline $(\mu \mathrm{c}-\mathrm{Si}: \mathrm{H})$ silicon at very low substrate temperatures $\left(\mathrm{T}_{\mathrm{sub}} \leq 150^{\circ} \mathrm{C}\right)$ due to the growing demand for new applications of thin film, large area microelectronics on portable, lightweight and inexpensive substrates, such as plastic. ${ }^{1-6}$ Deposition of these materials at low temperatures with good optoelectronic properties will not only allow the fast extension of some existing areas of large-area microelectronics (flat panel displays, image scanners or solar cells) to plastic substrates, but may also create entirely new applications such as integration of thin film electronics with biological materials, microelectromechanical devices fabricated on thin polymeric substrates, or throw-away electronics.

So far, there are few reported working devices entirely made of thin films deposited at very low $\mathrm{T}_{\text {sub }}\left(\leq 150^{\circ} \mathrm{C}\right)$. The first low-temperature amorphous thin film transistors (TFTs) reported were deposited on glass at $150^{\circ} \mathrm{C}$ by Feng et al., ${ }^{2}$ and at $125^{\circ} \mathrm{C}$ (with no $\mathrm{n}^{+}$contacts) by McCormick et al. ${ }^{3}$. Recently, the first TFTs on plastic were fabricated, at $125^{\circ} \mathrm{C}$ on polycarbonate by Gates, ${ }^{4}$ at $150^{\circ} \mathrm{C}$ on polyimide by Gleskova et al., ${ }^{5}$ and at $110{ }^{\circ} \mathrm{C}$ on polyethylene terephthalate by C.-S. Yang et al. ${ }^{6}$. The layers for the devices produced at $125^{\circ} \mathrm{C}$ were deposited by rf reactive magnetron sputtering while those produced at $150{ }^{\circ} \mathrm{C}$ and $110{ }^{\circ} \mathrm{C}$ used radio-frequency plasma-enhanced chemical vapor deposition (RF-PECVD). Both magnetron sputtering and RF-PECVD have low deposition rates for a-Si:H $(\sim 1 \AA \AA / s e c)$ and even lower for $\mu$ c-Si:H $(\sim 0.1$ $\AA / \mathrm{sec}$ ) which is usually obtained from hydrogen dilution of silane. For industrial applications, a high growth rate is attractive from a cost perspective because it decreases the process time and may increase the utilization efficiency of the process 
gases. At present, two techniques look promising to achieve higher growth rates. One is very-high frequency-PECVD which is being developed for $\mu \mathrm{c}-\mathrm{Si}: \mathrm{H}$ deposition at high rates and $\mathrm{T}_{\mathrm{sub}}=225^{\circ} \mathrm{C} .{ }^{7}$ The other is hot wire-CVD $(\mathrm{HW})$ which has been used to deposit a-Si:H and $\mu \mathrm{c}-\mathrm{Si}: \mathrm{H}$ at high rates $\left(r_{\mathrm{d}}>25 \AA / \mathrm{sec}\right.$ and $r_{\mathrm{d}}>5 \AA / \mathrm{sec}$, respectively) and at moderately high $\mathrm{T}_{\text {sub }}\left(>200^{\circ} \mathrm{C}\right)^{8,9,10,11}$. It is the high efficiency of the hot tungsten filament in breaking the molecules of the reactant gases, together with a high atomic hydrogen supply to the surface of the growing film, that is thought to allow the deposition of good quality amorphous and microcrystalline silicon films at high growth rate by $\mathrm{HW}$.

The capability to prepare heavily doped layers is critical for the performance of amorphous and microcrystalline thin film silicon devices. In TFTs and Schottky diodes, these doped layers are needed to make good ohmic contacts with the intrinsic layer and block the injection of carriers of the opposite sign. If these contacts are not able to supply sufficient carrier injection or collection, they create a series resistance in the on-state and thus limit the device performance. In p-i-n diodes, the built-in voltage depends on the position of the Fermi level of the $\mathrm{p}$ and $\mathrm{n}$ layers. Therefore, as the doping level increases, both in the $\mathrm{p}$ and $\mathrm{n}$ sides, the built-in voltage accordingly shifts to higher values, thus favoring the performance of the device.

$\mathrm{N}$-type and p-type a-Si:H deposited at high $\mathrm{T}_{\text {sub }}\left(220^{\circ} \mathrm{C}\right)$ by $\mathrm{HW}$ have values of $\sigma_{\mathrm{d}}$ above $10^{-3} \Omega^{-1} \mathrm{~cm}^{-1}$ and $\sim 10^{-5} \Omega^{-1} \mathrm{~cm}^{-1}$, respectively. ${ }^{12}$ These values are similar to those obtained in doped films by RF-PECVD. ${ }^{13}$ High $\mathrm{T}_{\text {sub }}\left(\geq 200^{\circ} \mathrm{C}\right)$ doped $\mu \mathrm{c}-\mathrm{Si}: \mathrm{H}$ films deposited by RF-PECVD have higher conductivity than doped amorphous films, in the range of $20-100 \Omega^{-1} \mathrm{~cm}^{-1}$ for n-type and up to $40 \Omega^{-1} \mathrm{~cm}^{-1}$ for p-type. ${ }^{14}$ 
Comparable values have been obtained for $\mu \mathrm{c}-\mathrm{Si}: \mathrm{H}$ films deposited at $\mathrm{T}_{\text {sub }} \geq 200^{\circ} \mathrm{C}$ by HW. ${ }^{10,15,16,17,18}$

In the present work, the doping n-type and p-type of a-Si:H and $\mu \mathrm{c}-\mathrm{Si}: \mathrm{H}$ by $\mathrm{HW}$ at substrate temperatures of $100^{\circ} \mathrm{C}$ and $25^{\circ} \mathrm{C}$ is studied systematically as a function of the hydrogen dilution and, to the best of our knowledge, this is the first study of doping by HW at these temperatures. The optimized conditions ${ }^{19}$ for deposition of intrinsic films at $100^{\circ} \mathrm{C}$ and $25^{\circ} \mathrm{C}$ were used as starting points for the deposition of the doped films.

\section{EXPERIMENTAL PROCEDURES}

\section{A. Film Preparation}

The films were deposited in an ultrahigh-vacuum-quality system with load lock, which has a base pressure better than $5 \times 10^{-8}$ Torr. The substrate was clamped to the grounded upper electrode. This electrode was, except for the room temperature depositions, heated to the deposition temperature, $\mathrm{T}_{\text {sub. }} \mathrm{T}_{\text {sub }}$ always refers to the temperature of the substrate before the filament was heated.

The substrate temperature was monitored using a thermocouple embedded in a copper block in contact with the substrate. The PET substrate is essentially transparent to the wavelengths of the radiation emitted by the filament. The pressure was kept constant at 20 mTorr. $^{9,12}$ At that pressure, both heat convection and conduction can be neglected. ${ }^{20}$ In this case the temperature of the PET substrate is the temperature of the substrate holder. For the nominal room-temperature deposition $\left(25^{\circ} \mathrm{C}\right)$, the temperature of the substrate holder can increase (up to $50^{\circ} \mathrm{C}$ ) due to the radiation from the filament. The maximum temperature $\left(50^{\circ} \mathrm{C}\right)$ was reached only for the deposition 
time of $13 \mathrm{~min}$ (which corresponds to the deposition of $\sim 0.50 \mu \mathrm{m}$ of a-Si:H; for the deposition of microcrystalline silicon films using high hydrogen dilution the growth rate is lower and 13 minutes corresponds to $\sim 0.13 \mu \mathrm{m}$ of $\mu \mathrm{c}-\mathrm{Si}: \mathrm{H}$ at $93.5 \%$ hydrogen dilution - see table I for the deposition rates). For deposition at $100^{\circ} \mathrm{C}$, the maximum observed increase in the temperature of the substrate during deposition was $9^{\circ} \mathrm{C}$ for a 13 minutes long deposition.

The gases (silane, hydrogen, phosphine and diborane), are introduced into the deposition chamber through a ring-shaped showerhead of $12.5 \mathrm{~cm}$ diameter located approximately $8 \mathrm{~cm}$ below the substrate holder. A phosphine-to-silane flow rate ratio of $0.4 \%$ was used for n-type doping while $1 \%$ diborane-to-silane flow rate ratio was used for p-type doping of amorphous films and $F_{\mathrm{B}_{2} \mathrm{H}_{6}} / \mathrm{F}_{\mathrm{SiH}_{4}}=0.5 \%$ for microcrystalline films. Hydrogen dilution is defined as $\mathrm{F}_{\mathrm{H}_{2}} /\left(\mathrm{F}_{\mathrm{SiH}_{4}}+\mathrm{F}_{\mathrm{H}_{2}}\right)$, where $\mathrm{F}_{\mathrm{H}_{2}}$ is the hydrogen flow rate and $\mathrm{F}_{\mathrm{SiH}_{4}}$ is the silane flow rate.

A single tungsten filament of $0.5 \mathrm{~mm}$ diameter and approximately $7 \mathrm{~cm}$ length was placed $5 \mathrm{~cm}$ from the substrate and was resistively heated with a DC power supply. The filament temperature was measured with an optical pyrometer $\left(\mathrm{T}_{\mathrm{fil}} \sim 2500{ }^{\circ} \mathrm{C}\right) .{ }^{9,12}$ The thickness of the films was between $\sim 0.1 \mu \mathrm{m}$ and $\sim 0.3 \mu \mathrm{m}$. The $\mu \mathrm{c}-\mathrm{Si}: \mathrm{H}$ films were, in general, thinner than the amorphous ones. The sum of the fluxes of the gases was kept at around $20 \mathrm{sccm}$, except for the higher dilutions where it was necessary to increase the fluxes so that the $\mathrm{SiH}_{4}$ flux was not less than $0.5 \mathrm{sccm}$, which was the lower limit for the silane mass flow controller. 


\section{B. Film Characterization.}

Films were deposited simultaneously on two different substrates: Corning 7059 glass and polyethylene terephthalate (PET). Electrical conductivity, constant photocurrent measurement (CPM) and Raman spectroscopy were performed on both substrates; $\mathrm{x}$ ray diffraction was performed only on samples deposited on glass.

The film thicknesses were measured with a Tencor profilometer. The dark conductivity, $\sigma_{\mathrm{d}}$, was measured between $110{ }^{\circ} \mathrm{C}$ and room temperature for samples deposited at $100^{\circ} \mathrm{C}$ and between $50^{\circ} \mathrm{C}$ and room temperature for samples deposited at room temperature to avoid annealing during the measurement. Coplanar $\mathrm{Cr}$ contacts, 6 mm long, $1 \mathrm{~mm}$ apart and approximately $1000 \AA$ thick were used. The activation energy $E_{\mathrm{a}}$ was calculated from $\sigma_{\mathrm{d}}=\sigma_{0} \exp \left[-E_{\mathrm{a}} /\left(k_{\mathrm{B}} T\right)\right]$. Photothermal deflection spectroscopy, PDS, and CPM were used to measure the sub-bandgap absorption, ${ }^{21,22}$ from which the defect density and bandtail slope can be extracted. ${ }^{23}$

Raman spectra were measured in the backscattering geometry using a Raman microprobe. The $514.5 \mathrm{~nm}(2.41 \mathrm{eV})$ laser radiation was obtained from an $\mathrm{Ar}^{+}$laser. The power of the incident beam was set below $50 \mathrm{~mW}$ to avoid thermally induced crystallization. For microcrystalline films, the Raman spectrum around the crystalline silicon transverse optical (TO) peak ${ }^{24}$ was deconvoluted into its integrated crystalline Gaussian peak, $I_{\mathrm{c}}\left(\sim 520 \mathrm{~cm}^{-1}\right)$, amorphous Gaussian peak, $I_{\mathrm{a}}\left(\sim 480 \mathrm{~cm}^{-1}\right)$, and intermediate Gaussian peak, $I_{\mathrm{m}}\left(\sim 510 \mathrm{~cm}^{-1}\right){ }^{25,26}$ The crystalline fraction, $X_{\mathrm{c}}$, was calculated from $X_{\mathrm{c}}=\left(I_{\mathrm{c}}+I_{\mathrm{m}}\right) /\left(I_{\mathrm{c}}+I_{\mathrm{m}}+I_{\mathrm{a}}\right){ }^{25}$

X-ray diffraction peaks were measured with a Siemens D-5000 x-ray diffractometer using the $\mathrm{Cu} K_{\alpha 1}$ line $(\lambda=1.54056 \AA)$. The samples were measured at grazing 
incidence $\left(0.5^{\circ}\right)$ using substrate holder rotation $(15 \mathrm{rpm})$. The crystallite size $d_{\mathrm{X} \text {-ray }}$ was calculated from the Scherrer formula $d_{\mathrm{X}-\mathrm{ray}}=k \lambda /\left(B \cos \theta_{\mathrm{B}}\right)$, where $k \sim 0.9, \lambda$ is the wavelength of the X-ray radiation, $B$ is the FWHM of the peaks (in units of $2 \theta$ ) and $\theta_{\mathrm{B}}$ is the angular position of the peak.

SIMS analysis was performed by Evans East (East Windsor, NJ) on samples deposited on glass substrates to detect boron (B) and phosphorous (P) concentration. Quantification of the profiles was accomplished by analyzing, along with the samples, an ion implanted reference material of $\mathrm{B}$ and $\mathrm{P}$ in $\mathrm{Si}$.

\section{RESULTS}

Figure 1 shows the room-temperature dark conductivity, $\sigma_{\mathrm{d}}$ (top), and the activation energy of the dark conductivity, $E_{\mathrm{a}}$ (bottom), of (a) p-type and (b) n-type samples deposited on glass at $\mathrm{T}_{\mathrm{sub}}=100^{\circ} \mathrm{C}$ and $25^{\circ} \mathrm{C}$ by $\mathrm{HW}$ as a function of hydrogen dilution. Also shown, as dotted lines, are the $\sigma_{\mathrm{d}}$ of intrinsic samples obtained at the same $\mathrm{T}_{\text {sub }}$. In general, the trends in the $\sigma_{\mathrm{d}}$ and $E_{\mathrm{a}}$ of the doped samples as a function of hydrogen dilution are similar to those of intrinsic samples, with $\sigma_{d}$ shifted to higher values (by a factor of $\left.10^{4}-10^{5}\right)$ and $E_{\mathrm{a}}$ to lower values $(\sim 0.25 \mathrm{eV})$ upon doping. This similarity in behavior is due to the fact that the electrical conductivities of both intrinsic and doped samples are very sensitive to whether the film is amorphous or microcrystalline. Table I shows the properties of selected doped amorphous and microcrystalline films deposited by HW. In general, films deposited on PET showed similar electrical and structural characteristics to those deposited on Corning glass. 


\section{A. p-type films.}

Figure 1 (a) shows that $\sigma_{d}$ of the p-type films deposited by HW is essentially $\mathrm{T}_{\text {sub }}$ independent. As the $\mathrm{H}_{2}$ dilution is increased from $80 \%$ to $93.5 \%, \sigma_{\mathrm{d}}$ increases from $\sim 10^{-7} \Omega^{-1} \mathrm{~cm}^{-1}\left(E_{\mathrm{a}} \sim 0.60 \mathrm{eV}\right)$ to $\sigma_{\mathrm{d}} \sim 1 \Omega^{-1} \mathrm{~cm}^{-1}\left(E_{\mathrm{a}} \sim 0.06 \mathrm{eV}\right)$. It can be concluded from the Raman spectra of fig. 2 that this increase in the $\sigma_{\mathrm{d}}$ is mainly due to a phase transition from an amorphous to a microcrystalline structure identified by the presence of a Raman resonance peak near $520 \mathrm{~cm}^{-1}\left(X_{\mathrm{c}}=65 \%\right.$ and $X_{\mathrm{c}}=60 \%$ for samples deposited at $100^{\circ} \mathrm{C}$ and $25^{\circ} \mathrm{C}$, respectively, using $93.5 \% \mathrm{H}_{2}$ dilution). The presence of the crystalline phase is confirmed by the XRD analysis of the films deposited at both $\mathrm{T}_{\text {sub }}=100^{\circ} \mathrm{C}$ (fig. 3 (a)) and $25^{\circ} \mathrm{C}$ (fig. 3 (c)) with grain sizes $d_{\mathrm{X} \text {-ray }} \sim 10-12 \mathrm{~nm}$. For ptype doping, the $\mathrm{a} \rightarrow \mu \mathrm{c}$ transition occurs at the same $\% \mathrm{H}_{2}$ dilution as for intrinsic films at both $\mathrm{T}_{\mathrm{sub}}=100^{\circ} \mathrm{C}$ and $\mathrm{T}_{\mathrm{sub}}=25^{\circ} \mathrm{C}$.

The boron concentration, [B] (table I), is between $1 \times 10^{20}$ and $3 \times 10^{20} \mathrm{~B}$-atom/ $/ \mathrm{cm}^{3}$ with the lower values in that range corresponding to the $\mu \mathrm{c}-\mathrm{Si}: \mathrm{H}$ samples. The distribution coefficients $^{27}, d_{\mathrm{I}}$, defined as $\left[C_{\mathrm{B}}\right]_{\mathrm{film}} /\left[C_{\mathrm{B}}\right]_{\text {gas }}$ where $\left[C_{\mathrm{B}}\right]_{\mathrm{film}}$ is the boron atomic concentration in the film and $\left[C_{\mathrm{B}}\right]_{\mathrm{gas}}$ is the molecular concentration of the dopant in the reactant mixture, are between 0.67 and 0.42 for p-type films, decreasing slightly as the $\mathrm{H}_{2}$ dilution is increased.

\section{B. n-type films.}

Figure 1 (b) shows that $\sigma_{\mathrm{d}}$ of n-type films deposited at $\mathrm{T}_{\mathrm{sub}}=100^{\circ} \mathrm{C}$ increases steeply from $10^{-7} \Omega^{-1} \mathrm{~cm}^{-1}\left(E_{\mathrm{a}}=0.69 \mathrm{eV}\right)$ to $10^{-1} \Omega^{-1} \mathrm{~cm}^{-1}\left(E_{\mathrm{a}}=0.113 \mathrm{eV}\right)$ when hydrogen dilution is increased from $50 \%$ to $92.5 \%$. If the hydrogen dilution is increased beyond 92.5\%, $\sigma_{\mathrm{d}}$ decreases. Fig.2 (b) shows that the $92.5 \% \mathrm{H}_{2}$ dilution film is microcrystalline with a low crystalline fraction $(\sim 19 \%)$. The highest conductivity for 
an n-type a-Si:H deposited at $\mathrm{T}_{\mathrm{sub}}=100^{\circ} \mathrm{C}$ is $\sigma_{\mathrm{d}}=3.6 \times 10^{-4} \Omega^{-1} \mathrm{~cm}^{-1}\left(E_{\mathrm{a}}=0.32 \mathrm{eV}\right)$ at $90 \%$ $\mathrm{H}_{2}$ dilution, just prior to the amorphous-to-microcrystalline $(\mathrm{a} \rightarrow \mu \mathrm{c})$ transition. At $\mathrm{T}_{\text {sub }}=25^{\circ} \mathrm{C}$, films deposited using $\mathrm{H}_{2}$ dilution $\leq 50 \%$ are powdery and show poor adhesion to the substrate. The maximum $\sigma_{\mathrm{d}}$ observed was at $80 \% \mathrm{H}_{2}$ dilution with a value of $1.4 \times 10^{-6} \Omega^{-1} \mathrm{~cm}^{-1}$. For larger values of $\mathrm{H}_{2}$ dilution, the films deposited at $\mathrm{T}_{\mathrm{sub}}=25^{\circ} \mathrm{C}$ were not doped. $\sigma_{\mathrm{d}}$ of these samples is lower than the conductivity of corresponding intrinsic samples, indicating that the dopant atoms are inactive and that impurity incorporation has the effect of degrading the electronic properties of the material.

Both the Raman (fig.2 (a) and (b)) and the XRD (fig.3 (a) and (c)) spectra show that the amorphous to microcrystalline transition, which occurs between 80 and $90 \% \mathrm{H}_{2}$ dilution in intrinsic films, was delayed at $100^{\circ} \mathrm{C}$ and inhibited at $25^{\circ} \mathrm{C}$ by the addition of the phosphine to the reactive gas mixture. The $a \rightarrow \mu$ c transition occurs only at 92.5\% $\mathrm{H}_{2}$ dilution at $\mathrm{T}_{\text {sub }}=100^{\circ} \mathrm{C}$ (compared to $90 \%$ for intrinsic films) and does not occur at all at $25^{\circ} \mathrm{C}$ (for intrinsic films, the a $\rightarrow \mu$ c transition occurs also at $90 \% \mathrm{H}_{2}$ dilution at $\mathrm{T}_{\mathrm{sub}}=25^{\circ} \mathrm{C}$ ). At $\mathrm{T}_{\mathrm{sub}}=100^{\circ} \mathrm{C}$, the crystalline fraction decreases from $X_{\mathrm{c}}=87 \%$ in the intrinsic film to $19 \%$ in the $92.5 \% \mathrm{H}_{2}$ dilution n-type film and the grain size decreases from $d_{\text {X-ray }} \sim 40 \mathrm{~nm}$ to $d_{\text {X-ray }} \sim 10 \mathrm{~nm}$.

The dopant concentrations found in n-type samples (table I) are similar to those found in p-type films. The phosphorus concentration, [P], in films deposited at $\mathrm{T}_{\text {sub }}=100^{\circ} \mathrm{C}$ is essentially independent of the $\mathrm{H}_{2}$ dilution and is in the range $1.5-3 \times 10^{20} \mathrm{P}$-atoms $/ \mathrm{cm}^{3}$. At $\mathrm{T}_{\text {sub }}=25^{\circ} \mathrm{C}$ and $80 \% \mathrm{H}_{2}$ dilution, the $[\mathrm{P}]$ is roughly doubled to $>6 \times 10^{20}$ atoms $/ \mathrm{cm}^{3}$. The $d_{\mathrm{I}}$ is $1.2-1.5$ for films deposited at $\mathrm{T}_{\mathrm{sub}}=100^{\circ} \mathrm{C}$ and $\sim 3$ at $25^{\circ} \mathrm{C}$. 


\section{DISCUSSION}

\section{A. Low-T sub doping versus standard high-T sub doping}

$\mathrm{N}$-type $\mu \mathrm{c}-\mathrm{Si}: \mathrm{H}$ samples were obtained by $\mathrm{HW}$ at $\mathrm{T}_{\mathrm{sub}}=100^{\circ} \mathrm{C}$ with $\sigma_{\mathrm{d}} \sim 10^{-1} \Omega^{-1} \mathrm{~cm}^{-1}$. This value is at least $\sim 1$ order of magnitude lower than the value of $\sigma_{\mathrm{d}}$ obtained in HW n-type films deposited at $\mathrm{T}_{\mathrm{sub}}=250^{\circ} \mathrm{C}$ (table I). The difference can be attributed to the lower crystalline fraction and the smaller grain size in the lower- $\mathrm{T}_{\text {sub }}$ films. These two effects both contribute to the reduction of the carrier mobility. At $T_{\text {sub }}=25^{\circ} \mathrm{C}, \mathrm{n}$ type doping of $\mu \mathrm{c}-\mathrm{Si}: \mathrm{H}$ samples was not achieved: a very high phosphorous incorporation $\left([\mathrm{P}]>3 \times 10^{21} \mathrm{~cm}^{-3}\right)$ resulted in highly defective amorphous films. At low $\mathrm{T}_{\text {sub }}$, higher values of $\sigma_{\mathrm{d}}$ are obtained for $\mathrm{p}$-type $\mu \mathrm{c}-\mathrm{Si}: \mathrm{H}$ films than for n-type ones. At $\mathrm{T}_{\text {sub }}=100^{\circ} \mathrm{C}$ and $25^{\circ} \mathrm{C}$ p-type $\mu \mathrm{c}-\mathrm{Si}: \mathrm{H}$ films have structural properties $\left(X_{\mathrm{c}} \sim 60 \%-65 \%\right.$, $\left.d_{\mathrm{XRD}} \sim 10.5-12 \mathrm{~nm}\right)$ and conductivities $\left(\sigma_{\mathrm{d}} \sim 1 \quad \Omega^{-1} \mathrm{~cm}^{-1}\right)$ similar to boron-doped microcrystalline films with comparable thickness deposited at $\mathrm{T}_{\text {sub }}>200^{\circ} \mathrm{C}$ (table I and refs.12, 15, 16).

N-type a-Si:H films deposited at $100^{\circ} \mathrm{C}$ have structural and transport properties $\left(\sigma_{\mathrm{d}} \sim 5 \times 10^{-4} \Omega^{-1} \mathrm{~cm}^{-1}\right)$ close to high- $\mathrm{T}_{\mathrm{sub}}$ films $\left(\mathrm{T}_{\mathrm{sub}}=220^{\circ} \mathrm{C}, \sigma_{\mathrm{d}} \sim 5 \times 10^{-3} \Omega^{-1} \mathrm{~cm}^{-1}\right)$ deposited by $\mathrm{HW}$. At $\mathrm{T}_{\mathrm{sub}}=25^{\circ} \mathrm{C}$ the properties of the film degrade and the conductivity of n-type a-Si:H samples is $\sim 10^{-6} \Omega^{-1} \mathrm{~cm}^{-1}$. P-type a-Si:H films deposited by $\mathrm{HW}$ have low $\sigma_{\mathrm{d}}$, both at $\mathrm{T}_{\mathrm{sub}}=100^{\circ} \mathrm{C}$ and $25^{\circ} \mathrm{C}\left(\sigma_{\mathrm{d}}=5 \times 10^{-7} \Omega^{-1} \mathrm{~cm}^{-1}\right.$ and $\sigma_{\mathrm{d}}=8 \times 10^{-7}$ $\Omega^{-1} \mathrm{~cm}^{-1}$, respectively). These values compare negatively with the value of $\sigma_{\mathrm{d}} \sim 10^{-5}$ $\Omega^{-1} \mathrm{~cm}^{-1}$ obtained in $\mathrm{p}^{+} \mathrm{a}-\mathrm{Si}: \mathrm{H}$ films deposited at $\mathrm{T}_{\mathrm{sub}}=220^{\circ} \mathrm{C}$ using $\mathrm{B}\left(\mathrm{CH}_{3}\right)_{3}$ as dopant gas (Table 1 and ref.12).

\section{B. The control of defect density with $\mathrm{H}_{2}$ dilution}


Hydrogen plays an essential role in the equilibration of the amorphous silicon structure as it breaks weak bonds and passivates dangling bonds ${ }^{28}$. For substrate temperatures lower than $\sim 150^{\circ} \mathrm{C}$, it is known that the structure of RF-PECVD films grown from silane is kinetically limited ${ }^{29}$ due to the reduced hydrogen diffusion at the surface and in the bulk, thus resulting in a much more defective material. Hydrogen dilution (50-60\%) of silane allowed the deposition by HW of intrinsic a-Si:H films at substrate temperatures of $100^{\circ} \mathrm{C}$ and $25^{\circ} \mathrm{C}$ with improved structural and electronic properties when compared to samples deposited without hydrogen dilution. ${ }^{19}$ In the case of doping, the results of the previous sections showed that the most conductive ptype and n-type a-Si:H samples were also obtained with $\mathrm{H}_{2}$ dilution of the reactant gases. Figure 4 shows $\sigma_{d}$ of doped a-Si:H films plotted as a function of the defect density, measured by CPM, of intrinsic films deposited using the same experimental conditions. The figure suggests that there is a correlation between the doping efficiency and the conditions of deposition which yield intrinsic films with low number of subgap defects. This correlation is stronger in the case of n-type films than in the case of p-type ones.

For $[\mathrm{P}] \sim 10^{20} \mathrm{~cm}^{-3}$, one usually considers that approximately $1 \%$ of the dopant atoms are 4 -fold coordinated, and that, of these, about $10 \%$ give electrons to the bandtail, in standard n-type RF-PECVD a-Si:H prepared above the equilibration temperature. ${ }^{27}$ In this case, $n_{\mathrm{bt}} \sim 10^{17} \mathrm{~cm}^{-3}$, and a conductivity of $\sigma_{\mathrm{d}}=e \mu_{\mathrm{d}} n_{\mathrm{bt}} \sim 10^{-2} \Omega^{-1} \mathrm{~cm}^{-1}$ ( $e$ is the electron charge, $\mu_{\mathrm{d}} \sim 1 \mathrm{~cm}^{2} \mathrm{~V}^{-1} \mathrm{~s}^{-1}$ the drift mobility and $n_{\mathrm{bt}}$ the carrier concentration in the bandtail) is expected. For p-type a-Si:H, deposited above the equilibration temperature, a value of $\sigma_{\mathrm{d}}=e \mu_{\mathrm{d}} n_{\mathrm{bt}} \sim 10^{-5} \Omega^{-1} \mathrm{~cm}^{-1}$ is expected since $\mu_{\mathrm{d}} \sim 10^{-3} \mathrm{~cm}^{2} \mathrm{~V}^{-1} \mathrm{~s}^{-1}$ [ref. 28]. These estimated values are in good agreement with those observed for doped HW films deposited at $\mathrm{T}_{\mathrm{sub}}=220^{\circ} \mathrm{C}$. For $\mathrm{HW}$ films deposited at $25^{\circ} \mathrm{C}$ and $100^{\circ} \mathrm{C}$, the 
intrinsic dangling bond density increases from a value of $N_{\mathrm{D}} \sim 10^{16} \mathrm{~cm}^{-3}$, obtained at $\mathrm{T}_{\text {sub }}=220^{\circ} \mathrm{C},{ }^{30}$ to $N_{\mathrm{D}^{\sim}} 10^{17} \mathrm{~cm}^{-3}$ for $\mathrm{T}_{\text {sub }}=100^{\circ} \mathrm{C}$ and $N_{\mathrm{D}} \sim 10^{18} \mathrm{~cm}^{-3}$ for $\mathrm{T}_{\text {sub }}=25^{\circ} \mathrm{C}$ (fig. 4 and ref.19). For a constant active dopant concentration, $N_{\text {donor }} \sim 10^{17} \mathrm{~cm}^{-3}$, and assuming similar values of dangling bonds in the doped films, doping should be less efficient at these low- $\mathrm{T}_{\text {sub }}$ because nearly all the dopants would be compensated by deep defects. The carriers that contribute to the conduction, $n_{\mathrm{bt}}$, are only those which are not trapped in deep defects - a very small fraction of the number of active dopants - and so a small change in $N_{\mathrm{D}}$ can cause an important relative change in $n_{\mathrm{bt}}$. The beneficial role of atomic hydrogen in $\mathrm{H}_{2}$-assisted deposition is most likely related to the passivation of dangling bonds, paralleling the case for intrinsic a-Si:H films, rather than to the activation of the donor or acceptor atoms. In fact, as will be discussed in next section, the reactivity of hydrogen with phosphorous and, especially, with boron in the doped films leads to the passivation of donors and acceptors, respectively.

\section{Dopant activation in a-Si:H and $\mu \mathrm{C}-\mathrm{Si}: \mathrm{H}$ films}

To further understand doping in low- $\mathrm{T}_{\text {sub }} \mathrm{HW}$ silicon thin films, irreversible isochronal annealing of selected amorphous and microcrystalline samples was performed with increasing annealing temperatures. Samples were annealed for one hour at each temperature. The temperature increment was $50^{\circ} \mathrm{C}$, starting at $100^{\circ} \mathrm{C}$ and ending at $200^{\circ} \mathrm{C}$. The dark conductivity of the samples was measured after each annealing step. The results are shown in fig.5 (p-type) and fig.6 (n-type).

Figs. 5 and 6 show that $\sigma_{\mathrm{d}}$ of microcrystalline films does not change significantly upon annealing while $\sigma_{\mathrm{d}}$ of the amorphous films increases after annealing. This means that in microcrystalline samples the dopants were already essentially fully activated in the as-deposited state. The low- $\sigma_{\mathrm{d}}$ p-type a-Si:H films deposited at both $\mathrm{T}_{\mathrm{sub}}=100^{\circ} \mathrm{C}$ 
and $25^{\circ} \mathrm{C}$ fully recovered the conductivity $\sigma_{\mathrm{d}}=3 \times 10^{-5} \Omega^{-1} \mathrm{~cm}^{-1}$ typical of boron doped films deposited at $\mathrm{T}_{\mathrm{sub}} \sim 200^{\circ} \mathrm{C}$ upon annealing (fig.5). The n-type sample deposited at $\mathrm{T}_{\text {sub }}=100^{\circ} \mathrm{C}$ kept its $\sigma_{\mathrm{d}}$ essentially constant $\left(\sim 10^{-3} \Omega^{-1} \mathrm{~cm}^{-1}\right)$ after each annealing step. This is consistent with the explanation that the deposition temperature was already near or higher than the equilibration temperature of the phosphorous doped a-Si:H structure which is thought to be $\sim 110^{\circ} \mathrm{C}$ for standard RF-PECVD deposition. ${ }^{29}$ The $\sigma_{\mathrm{d}}$ of the n-type a-Si:H film deposited at $\mathrm{T}_{\mathrm{sub}}=25^{\circ} \mathrm{C}$ increased until $\sigma_{\mathrm{d}} \sim 10^{-4} \Omega^{-1} \mathrm{~cm}^{-1}$ partially recovering the $\sigma_{\mathrm{d}}$ typical of films deposited at $\mathrm{T}_{\mathrm{sub}} \sim 200^{\circ} \mathrm{C}$.

Annealing can induce two different transformations that explain the observed increase in the $\sigma_{\mathrm{d}}$ of a-Si:H films. On the one hand, the number of impurity atoms that adopt the host 4-fold configuration, and thus become active donors or acceptors, may increase. On the other hand, annealing of the native intrinsic defects can also increase the doping efficiency.

The largest increase in the value of $\sigma_{\mathrm{d}}$ of doped a-Si:H films after annealing is observed in p-type films (fig.5). This behavior can be explained by the formation, in these hydrogen-rich low- $\mathrm{T}_{\text {sub }}$ a-Si:H films, of boron-hydrogen complexes, which are stable until temperatures above $100^{\circ} \mathrm{C} .^{31,32}$ The hydrogen content measured by infrared spectroscopy in intrinsic films deposited by HW using the same $\mathrm{H}_{2}$ dilution and similar deposition conditions used for doping was $\sim 15$ atom $\%$ for $\mathrm{T}_{\text {sub }}=25^{\circ} \mathrm{C}$, $100^{\circ} \mathrm{C}$ and $175^{\circ} \mathrm{C}$ and $\sim 7.5$ atom $\%$ for $\mathrm{T}_{\text {sub }}=220^{\circ} \mathrm{C} .{ }^{19}$ These complexes are formed between hydrogen atoms that are bonded to silicon and B-atoms that are in the 3-fold non-doping configuration and in this way become stabilized in that configuration at the substrate temperature. As the annealing temperature increases, these weak B-H bonds are broken when the hydrogen mobility increases in the silicon network. 
Consequently, a growing quantity of B-atoms becomes free to adopt a 4-fold configuration and the doping efficiency increases. The phosphorous-hydrogen complexes that form in n-type a-Si:H are much less stable than the B-H ones and are fully dissociated above $\sim 60^{\circ} \mathrm{C}$ (ref.33). In agreement with this observation, the n-type a-Si:H film deposited at $\mathrm{T}_{\mathrm{sub}}=100^{\circ} \mathrm{C}$ showed only a slight increase in $\sigma_{\mathrm{d}}$, from $3.6 \times 10^{-}$ ${ }^{4} \Omega^{-1} \mathrm{~cm}^{-1}$ to $9.6 \times 10^{-4} \Omega^{-1} \mathrm{~cm}^{-1}$ upon annealing. The film deposited at $\mathrm{T}_{\mathrm{sub}}=25^{\circ} \mathrm{C}$ showed a larger increase in $\sigma_{\mathrm{d}}$, from $\sigma_{\mathrm{d}}=1.4 \times 10^{-6} \Omega^{-1} \mathrm{~cm}^{-1}$ to $\sigma_{\mathrm{d}}=6.6 \times 10^{-5} \Omega^{-1} \mathrm{~cm}^{-1}$. The film deposited at $\mathrm{T}_{\mathrm{sub}}=25^{\circ} \mathrm{C}$ using high hydrogen dilution (92.5\%) which was not doped and was Raman amorphous in the as-deposited state gradually increased its conductivity until $\sigma_{\mathrm{d}}=2.7 \times 10^{-7} \Omega^{-1} \mathrm{~cm}^{-1}$ after annealing at $200^{\circ} \mathrm{C}$.

In order to assess the relative contribution of both processes - dopant activation and defect annealing - intrinsic films deposited using the same $\mathrm{T}_{\text {sub }}$ and $\mathrm{H}_{2}$ dilution and otherwise similar deposition conditions to those used in the doped films, were annealed at $200^{\circ} \mathrm{C}$ for one hour. Dark conductivity, $\sigma_{\mathrm{d}}\left(\sigma_{\mathrm{d}}=7.0 \times 10^{-10} \Omega^{-1} \mathrm{~cm}^{-1}\right.$ and $\sigma_{\mathrm{d}}=1.9 \times 10^{-9} \Omega^{-1} \mathrm{~cm}^{-1}$ for the films deposited at $\mathrm{T}_{\mathrm{sub}}=25^{\circ} \mathrm{C}$ and $100^{\circ} \mathrm{C}$, respectively) and photoconductivity, $\sigma_{\mathrm{ph}}\left(\sigma_{\mathrm{ph}}=5.2 \times 10^{-6} \Omega^{-1} \mathrm{~cm}^{-1}\right.$ and $\sigma_{\mathrm{ph}}=1.2 \times 10^{-5} \Omega^{-1} \mathrm{~cm}^{-1}$ at $\mathrm{T}_{\mathrm{sub}}=25^{\circ} \mathrm{C}$ and $100^{\circ} \mathrm{C}$, respectively) of the intrinsic films showed only relatively small changes and did not approach the higher values $\left(\sigma_{\mathrm{ph}}>10^{-3} \Omega^{-1} \mathrm{~cm}^{-1}, \sigma_{\mathrm{ph}} / \sigma_{\mathrm{d}} \geq 10^{6}\right)$ characteristic of intrinsic a-Si:H films deposited by $\mathrm{HW}$ at the annealing temperature, $\mathrm{T}_{\text {sub }} \sim 200^{\circ} \mathrm{C}$.

It is possible to conclude that dopant activation is the dominant mechanism explaining the large increase in $\sigma_{\mathrm{d}}$ of the p-type films upon annealing. In the case of the much smaller improvement observed in the $\sigma_{d}$ of n-type films deposited at $25^{\circ} \mathrm{C}$ both processes - dopant activation and defect annealing - could have comparable importance. 


\section{Crystallinity of low-T sub doped films}

The addition of dopant gases to the reactive gas mixture had a detrimental effect on the crystallization of films deposited under high $\mathrm{H}_{2}$ dilution at low $\mathrm{T}_{\text {sub }}$. This effect is reflected in the following observations: the crystalline fraction in doped films was always smaller than that obtained for intrinsic films prepared at the same $\mathrm{T}_{\text {sub }}$ using the same hydrogen dilution (fig. 2); the crystallite size was reduced with respect to the intrinsic films (fig. 3); and the $a \rightarrow \mu$ transition in n-type films required higher values of $\mathrm{H}_{2}$ dilution than for intrinsic material (fig. 1). Dopant incorporation possibly causes high levels of distortion in the small host crystallites thus reducing the tendency towards crystallization. This effect was more pronounced in doping with $\mathrm{PH}_{3}$ where films deposited at room temperature were amorphous to the Raman, even at very high $\mathrm{H}_{2}$ dilutions (92.5\%). $\mathrm{B}_{2} \mathrm{H}_{6}$ had no observable effect on the $\mathrm{H}_{2}$ dilution value necessary for the a $\rightarrow \mu \mathrm{c}$ transition in films deposited by HW but the crystalline fraction in boron-doped $\mu \mathrm{c}-\mathrm{Si}: \mathrm{H}$ films was smaller than in intrinsic microcrystalline films by HW (fig. 2).

\section{E. The effect of the plastic substrate on crystallization}

$\sigma_{\mathrm{d}}$ and $E_{\mathrm{a}}$ of doped films deposited on glass and on PET are, within the error of the measurements, identical (see table I). This indicates that the mechanism of nucleation and growth of doped amorphous and microcrystalline films on glass and on PET are similar.

In microcrystalline films, a higher crystalline fraction is generally observed for films deposited on PET than for films deposited on glass using the same $T_{\text {sub }}$ and $\mathrm{H}_{2}$ dilution (see Table I), although the film conductivity in both substrates is similar. This could be attributed to the lower level of intrinsic stress present in the films due to the 
higher compliance of the plastic substrate when compared to glass. A relaxation of the film structure, due to energy transfer through the film-substrate interface as elastic or plastic deformation, at the onset of crystalline growth, could benefit the growth of $\mu \mathrm{c}-$ film on plastic more than on glass, where this effect is minute.

\section{CONCLUSIONS}

The electronic, optical and structural properties of gas phase doped amorphous and microcrystalline silicon thin films deposited at substrate temperatures of $25^{\circ} \mathrm{C}$ and $100^{\circ}$ by hot-wire chemical vapor deposition were studied as functions of hydrogen dilution. Films were deposited on glass and polyethylene terephthalate (PET).

If a lower limit of $10^{-6} \Omega^{-1} \mathrm{~cm}^{-1}$ is set for the $\sigma_{\mathrm{d}}$ of doped a-Si:H films and of $10^{-2}$ $\Omega^{-1} \mathrm{~cm}^{-1}$ for doped $\mu \mathrm{c}-\mathrm{Si}: \mathrm{H}$ for these films to be considered acceptable as contact layers in thin-film devices, then it is possible to assess the viability of the processes studied. N-type a-Si:H with $\sigma_{\mathrm{d}} \geq 10^{-6} \Omega^{-1} \mathrm{~cm}^{-1}$ can be deposited by $\mathrm{HW}$ at $\mathrm{T}_{\mathrm{sub}}=100^{\circ} \mathrm{C}$ and $25^{\circ} \mathrm{C}$ (at $90 \%$ and $80 \% \mathrm{H}_{2}$ dilution, respectively). P-type a-Si:H doping was achieved with a $\sigma_{\mathrm{d}} \sim 10^{-6} \Omega^{-1} \mathrm{~cm}^{-1}$ only at $\mathrm{T}_{\mathrm{sub}}=100^{\circ} \mathrm{C}\left(50 \% \mathrm{H}_{2}\right.$ dilution $)$. N-type and $\mathrm{p}-$ type doping of $\mu \mathrm{c}$-Si:H was achieved using $\mathrm{HW}$ at $100^{\circ} \mathrm{C}$. At $25^{\circ} \mathrm{C}$, only p-type doping of $\mu \mathrm{c}-\mathrm{Si}: \mathrm{H}$ was achieved by HW. Doping is more difficult at low substrate temperatures in the amorphous films, because of the formation of hydrogen-boron complexes and of the higher defect density, and, in the microcrystalline films, because the addition of dopant gases to the gas mixture during deposition decreases the crystalline fraction of the films. It is concluded that, within the limitations described above, it is possible to prepare adequately doped p-type and n-type contact layers at $\mathrm{T}_{\mathrm{sub}} \leq 100^{\circ} \mathrm{C}$ on glass and plastic substrates by HW-CVD. 


\section{ACKNOWLEDGEMENTS}

The authors thank N. Louro for help with annealing measurements and P. Brogueira for discussions related to the estimation of the surface temperature. The authors thank R. Almeida (IST/INESC) for the use of the Raman equipment and L. Paramés and O. Conde of the Faculty of Sciences of the University of Lisbon for the use of the X-ray diffraction equipment. This work was supported by the Fundação para a Ciência e Tecnologia (FCT) through Pluriannual Contracts with UCES/ICEMS (IST) and INESC and by projects in the Praxis program. One of the authors (P.A.) thanks the Department of Physics of University of Minho for a leave of absence. 
Table I. Properties of selected n-type and p-type a-Si:H and $\mu \mathrm{c}-\mathrm{Si}: \mathrm{H}$ samples.

\begin{tabular}{|c|c|c|c|c|c|c|c|c|c|c|c|c|c|}
\hline $\begin{array}{l}T_{\text {sub }} \\
\left({ }^{\circ} \mathrm{C}\right)\end{array}$ & Sample & $\begin{array}{l}\mathrm{H}_{2} \text { dil } \\
(\%)\end{array}$ & $\begin{array}{l}\text { dopant } \\
\text { gas }\end{array}$ & $\begin{array}{l}\frac{F_{\text {dopant }}}{F_{\mathrm{SiH}_{4}}} \\
\times 100 \%\end{array}$ & $\begin{array}{c}r_{\mathrm{d}} \\
(\AA / \mathrm{A} / \mathrm{s})\end{array}$ & $\begin{array}{l}{[\mathrm{P}] \text { or }[\mathrm{B}]} \\
\text { from } \\
\text { SIMS } \\
\left(\mathrm{atm} . \mathrm{cm}^{-3}\right)\end{array}$ & $\begin{array}{c}X_{\mathrm{c}}^{\text {Raman }} \\
(\%)\end{array}$ & $\begin{array}{c}X_{\mathrm{c}}^{\text {Ramant }} \\
(\%) \\
\text { on PET }\end{array}$ & $\begin{array}{l}d_{\mathrm{XRD}} \\
(\mathrm{nm})\end{array}$ & $\begin{array}{c}\sigma_{d} \\
\left(\Omega^{-1} \mathrm{~cm}^{-1}\right)\end{array}$ & $\begin{array}{c}\sigma_{d}^{\dagger} \\
\left(\Omega^{-1} \mathrm{~cm}^{-1}\right) \\
\text { on PET }\end{array}$ & $\begin{array}{l}E_{a, d} \\
(\mathrm{eV})\end{array}$ & $\begin{array}{c}E_{a, d^{\dagger}} \\
(\mathrm{eV}) \\
\text { on PET }\end{array}$ \\
\hline 25 & N1701 & 80 & $\mathrm{PH}_{3}$ & $1 \%$ & 4.7 & $6.5 \times 10^{20}$ & amorph. & amorph. & & $1.4 \times 10^{-6}$ & $3.7 \times 10^{-6}$ & 0.560 & 0.528 \\
\hline 25 & P1692 & 50 & $\mathrm{~B}_{2} \mathrm{H}_{6}$ & $1 \%$ & 6.7 & $\begin{array}{l}2.9 \times 10^{20} \\
(1)\end{array}$ & amorph. & amorph. & & $5.0 \times 10^{-7}$ & $3.8 \times 10^{-8}$ & 0.662 & 0.641 \\
\hline 25 & P1695 & 93.5 & $\mathrm{~B}_{2} \mathrm{H}_{6}$ & $0.5 \%$ & 1.8 & $\begin{array}{l}7.9 \times 10^{19} \\
\text { (2) }\end{array}$ & 60 & 60 & 12.0 & 1.5 & 0.87 & 0.050 & 0.034 \\
\hline 100 & N1640 & 90 & $\mathrm{PH}_{3}$ & $0.4 \%$ & 1.6 & $1.5 \times 10^{20}$ & amorph. & amorph. & & $3.6 \times 10^{-4}$ & $1.9 \times 10^{-4}$ & 0.320 & 0.343 \\
\hline 100 & N1649 & 92.5 & $\mathrm{PH}_{3}$ & $0.4 \%$ & 1.3 & $1.7 \times 10^{20}$ & 19 & 61 & 10.5 & 0.10 & $6.9 \times 10^{-2}$ & 0.113 & 0.145 \\
\hline 100 & P1680 & 50 & $\mathrm{~B}_{2} \mathrm{H}_{6}$ & $1 \%$ & 6.4 & $3.4 \times 10^{20}$ & amorph. & amorph. & & $8.0 \times 10^{-7}$ & $7.7 \times 10^{-7}$ & 0.640 & 0.577 \\
\hline 100 & P1689 & 90 & $\mathrm{~B}_{2} \mathrm{H}_{6}$ & $0.5 \%$ & 1.7 & $1.0 \times 10^{20}$ & 45 & 61 & 10.2 & 0.32 & 0.35 & 0.040 & 0.017 \\
\hline 100 & P1690 & 93.5 & $\mathrm{~B}_{2} \mathrm{H}_{6}$ & $0.5 \%$ & 1.7 & $1.1 \times 10^{20}$ & 65 & 72 & & 0.89 & 0.26 & 0.060 & 0.041 \\
\hline 220 & IS266 & 50 & $\mathrm{PH}_{3}$ & $2 \%$ & $28^{\dagger \dagger}$ & $5.8 \times 10^{20}$ & amorph. & - & & $5.8 \times 10^{-3}$ & - & 0.25 & - \\
\hline 250 & N1673 & 92.5 & $\mathrm{PH}_{3}$ & $0.4 \%$ & 1.7 & $1.6 \times 10^{20}$ & 51 & - & 13.8 & 1.5 & - & 0.05 & - \\
\hline 220 & IS 232 & 50 & $\mathrm{~B}\left(\mathrm{CH}_{3}\right)_{3}$ & $1 \%$ & $29^{\dagger \dagger}$ & $2.7 \times 10^{19}$ & amorph. & - & & $8.4 \times 10^{-6}$ & - & 0.44 & - \\
\hline 250 & P1717 & 92.5 & $\mathrm{~B}_{2} \mathrm{H}_{6}$ & $0.5 \%$ & 1.6 & $5.9 \times 10^{19}$ & 63 & - & 10.2 & 1.3 & - & 0.04 & - \\
\hline
\end{tabular}

Property measured on film deposited on polyethylene terephthalate (PET) substrate.

${ }^{\dagger}$ Deposited using filament-to-substrate distance equal to $3 \mathrm{~cm}$.

(1)for film deposited with $80 \% \mathrm{H}_{2}$ dilution.

(2) for film deposited with $92.5 \% \mathrm{H}_{2}$ dilution. 


\section{FIGURE CAPTIONS}

FIG. 1. $\sigma_{d}$ (top) and $E_{a}$ (bottom) of p-type ((a), open symbols) and n-type ((b), solid symbols) films deposited by $\mathrm{HW}$ at $\mathrm{T}_{\mathrm{sub}}=100^{\circ} \mathrm{C}$ (squares) and $\mathrm{T}_{\mathrm{sub}}=25^{\circ} \mathrm{C}$ (circles) on glass substrates as a function of hydrogen dilution. Phosphine to silane flow rate ratio used for n-type doping was $0.4 \%$; diborane to silane flow rate ratio used for p-type doping was: (i) $1 \%$ for $50 \%$ and $80 \%$ hydrogen dilution and (ii) $0.5 \%$ for hydrogen dilution $>80 \%$. Also shown are the $\sigma_{d}$ of intrinsic samples obtained at $\mathrm{T}_{\text {sub }}=25^{\circ} \mathrm{C}$ (dots) and $\mathrm{T}_{\mathrm{sub}}=100^{\circ} \mathrm{C}$ (short dashes).

FIG. 2. Raman spectra of n-type and p-type films deposited by $\mathrm{HW}$ at $\mathrm{T}_{\mathrm{sub}}=25^{\circ} \mathrm{C}$ (a) and $\mathrm{T}_{\mathrm{sub}}=100^{\circ} \mathrm{C}(\mathrm{b})$ at high $\mathrm{H}_{2}$ dilution on glass substrates. Also shown are spectra of intrinsic microcrystalline films deposited at the same $\mathrm{T}_{\text {sub }}$ using comparable $\mathrm{H}_{2}$ dilutions.

FIG. 3. X-ray spectra of $\mu \mathrm{c}$-Si:H films (a) p-type film deposited at $100{ }^{\circ} \mathrm{C}$; (b) n-type film deposited at $100{ }^{\circ} \mathrm{C}$; (c) p-type film deposited at $25^{\circ} \mathrm{C}$; and (d) n-type film deposited at $25{ }^{\circ} \mathrm{C}$. An x-ray spectrum of an intrinsic film is shown for comparison. The vertical scales used to plot the results of the doped films are $7 x$ that of the intrinsic film.

FIG. 4. $\sigma_{\mathrm{d}}$ of n-type and p-type a-Si:H deposited at $\mathrm{T}_{\text {sub }}=25^{\circ} \mathrm{C}, 100^{\circ} \mathrm{C}$ and $220^{\circ} \mathrm{C}$ as a function of the dangling bond concentration, $N_{\mathrm{D}}$, measured by CPM, in the corresponding intrinsic film (deposited using the same $\mathrm{T}_{\text {sub }}$ and $\mathrm{H}_{2}$ dilution).

FIG. 5. $\sigma_{\mathrm{d}}$ of p-type a-Si:H and $\mu \mathrm{c}-\mathrm{Si}: \mathrm{H}$ films as-deposited, after 6 months at room temperature and after three annealing steps of one hour at increasing annealing temperature. 
FIG. 6. $\sigma_{d}$ of n-type a-Si:H and $\mu \mathrm{c}-\mathrm{Si}: \mathrm{H}$ films as-deposited, after 6 months at room temperature and after three annealing steps of one hour at increasing annealing temperature. 
Figure 1, P. Alpuim, Journal of Vacuum Science and Technology A

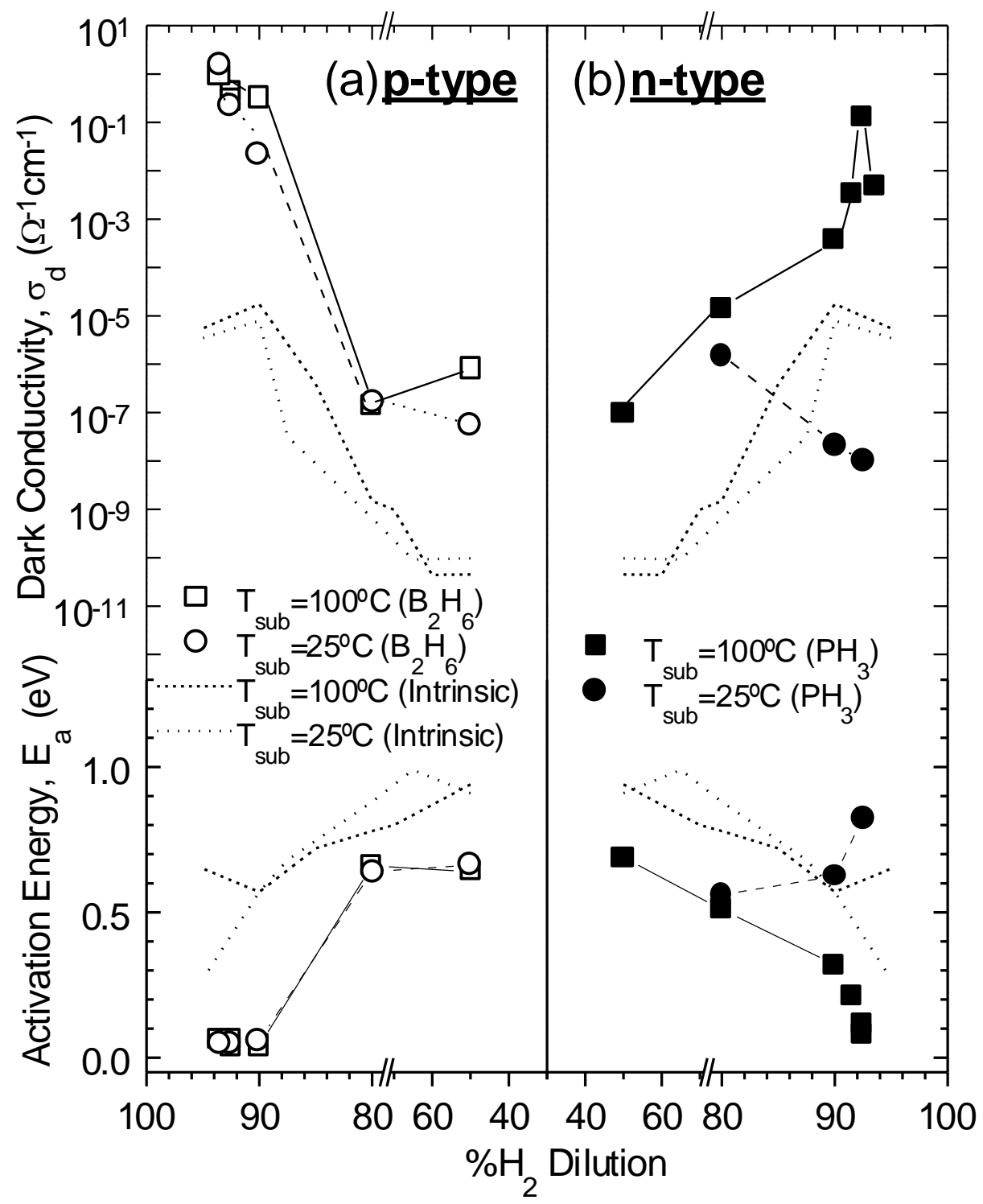


Figure 2, P. Alpuim, Journal of Vacuum Science and Technology A

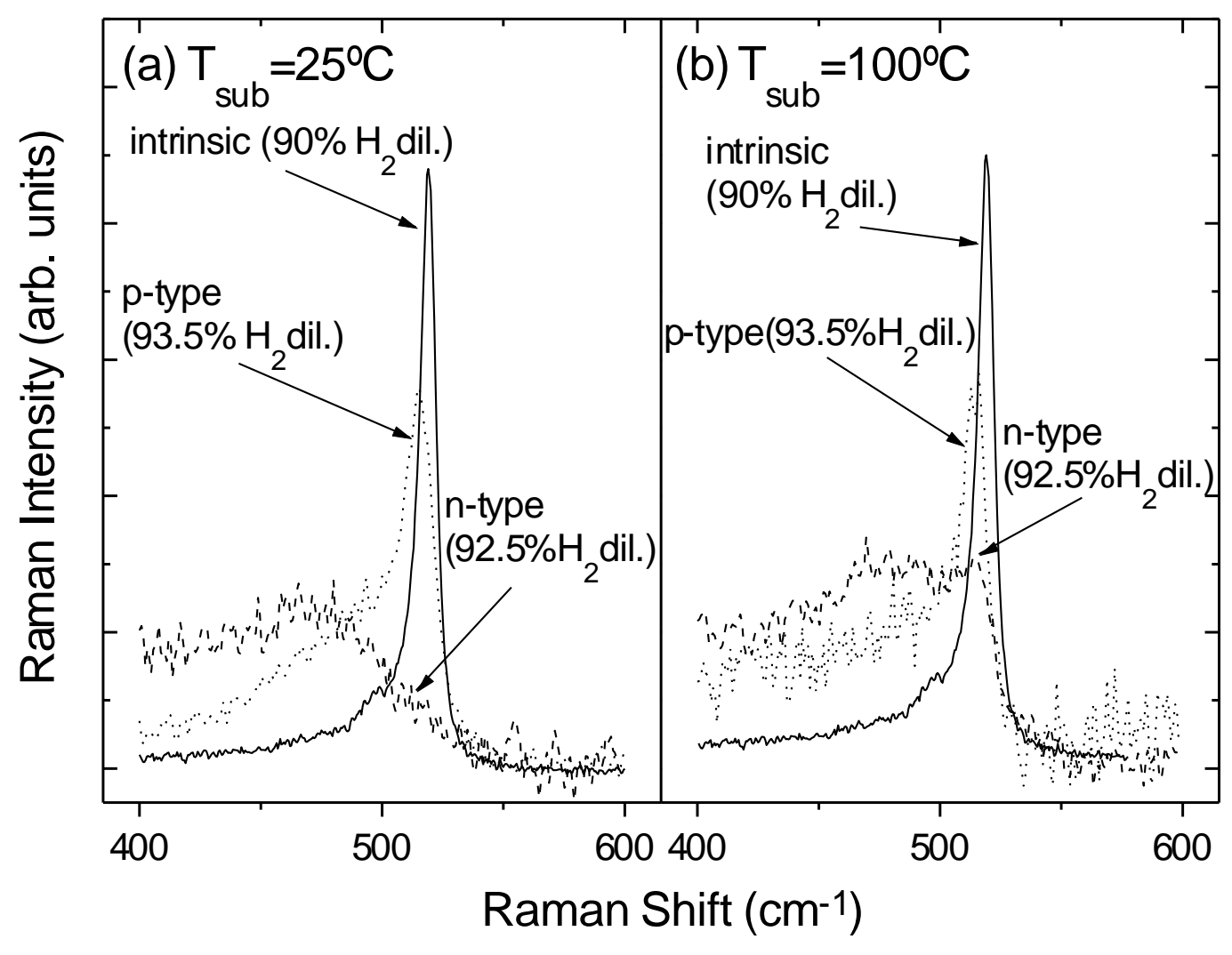


Figure 3, P. Alpuim, Journal of Vacuum Science and Technology A

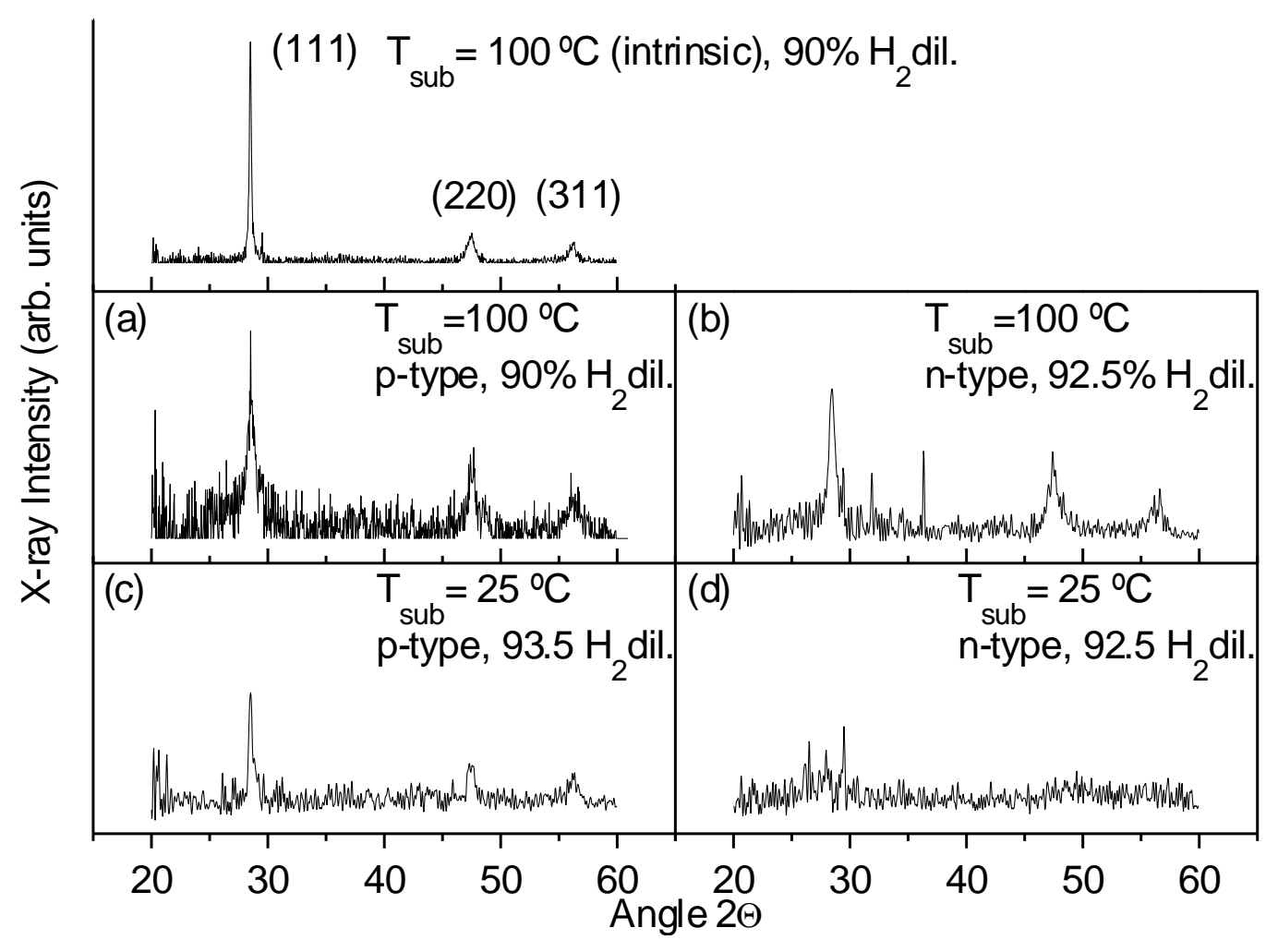


Figure 4, P. Alpuim, Journal of Vacuum Science and Technology A

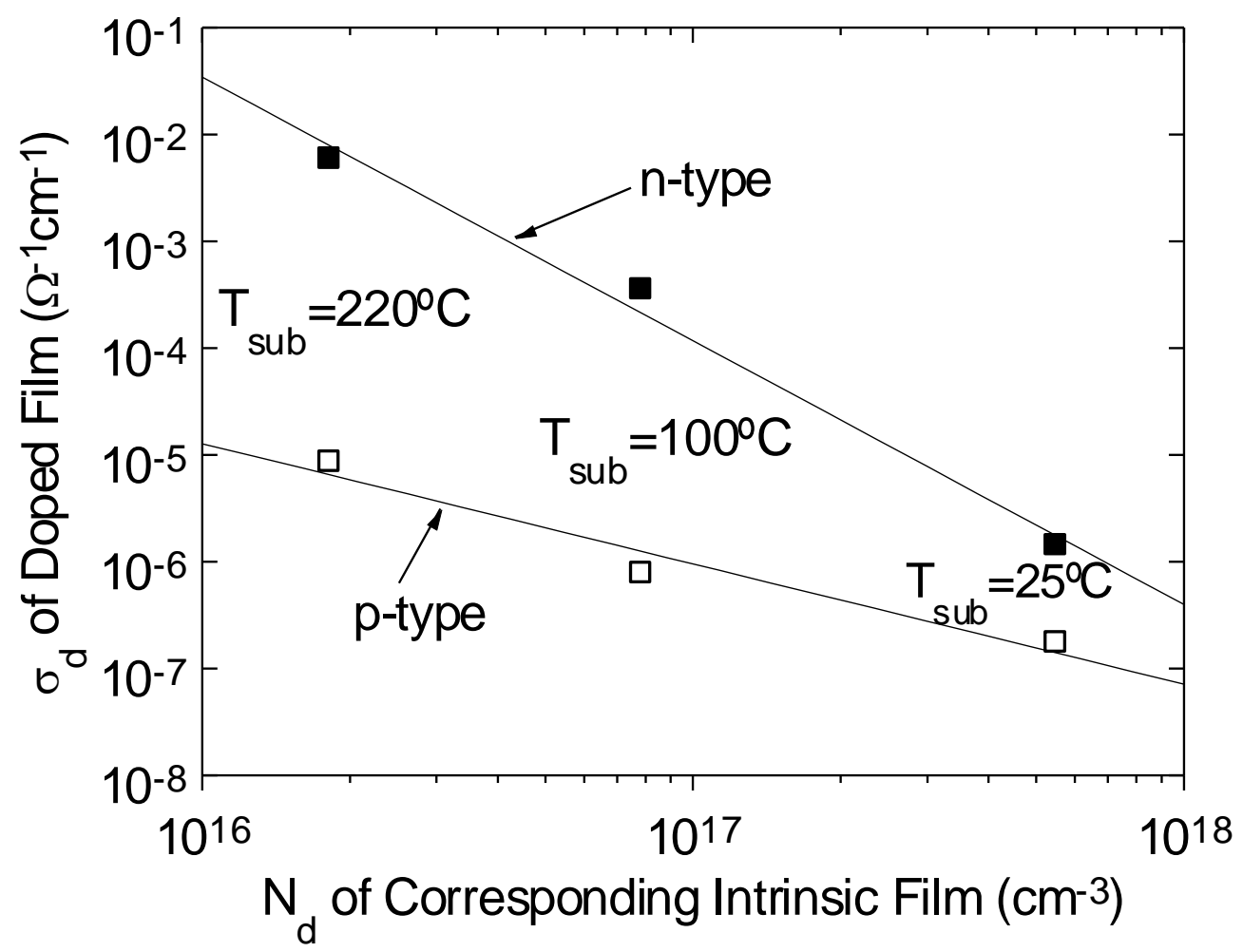


Figure 5, P. Alpuim, Journal of Vacuum Science and Technology A

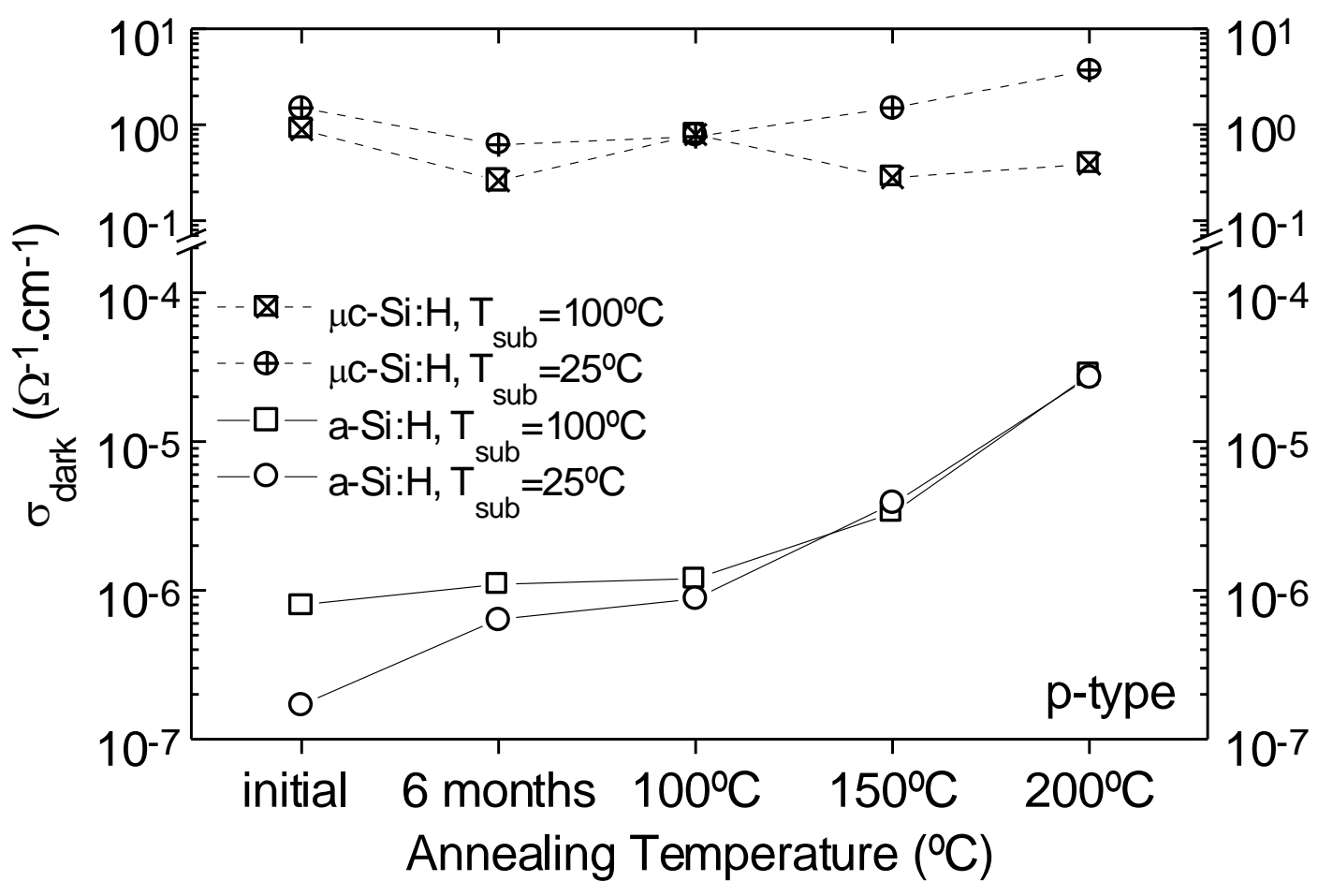


Figure 6, P. Alpuim, Journal of Vacuum Science and Technology A

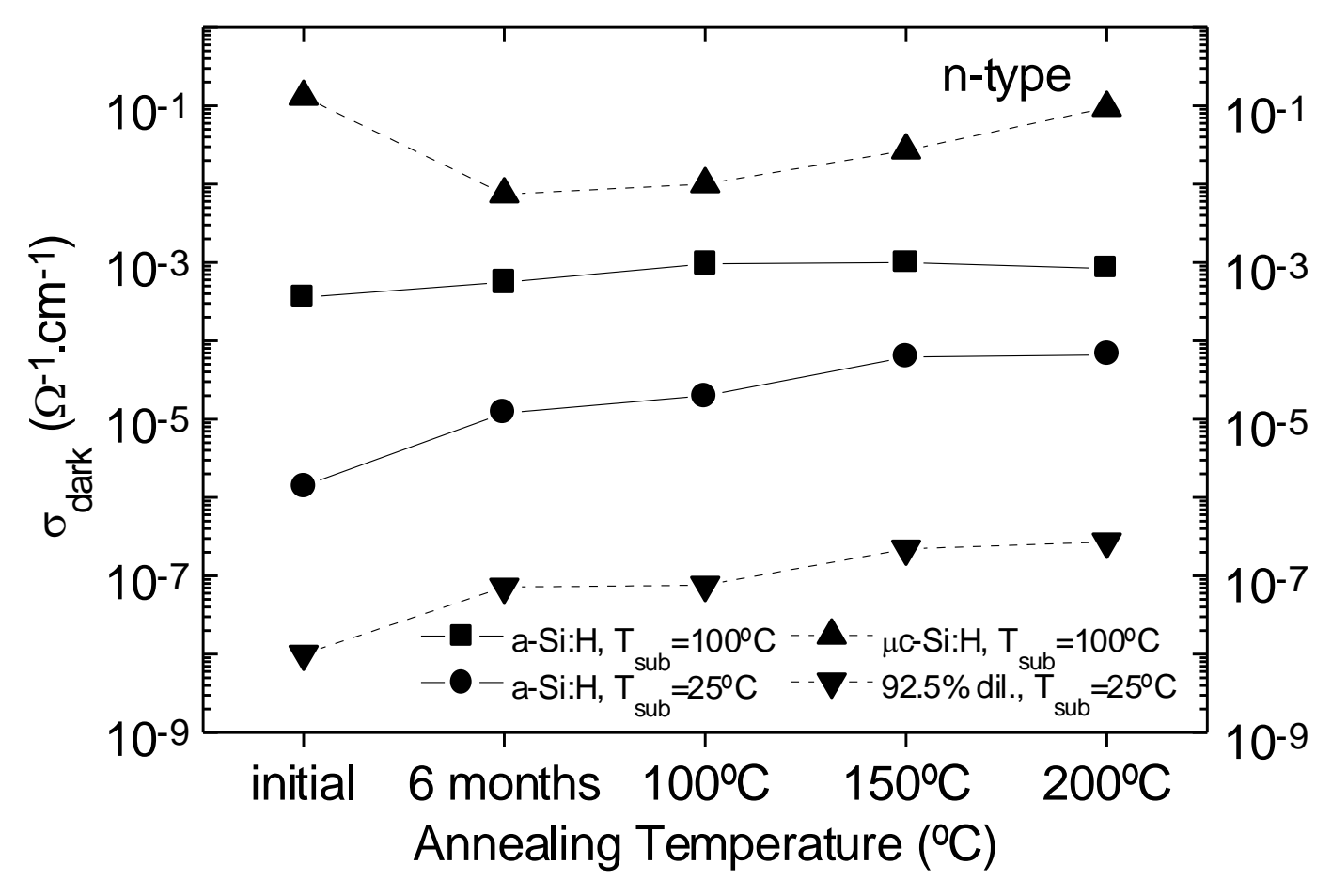




\section{REFERENCES}

${ }^{1}$ V. Lumelsky, M. S. Shur, S. Wagner, Sensitive Skin (World Scientific Publ. Comp., Inc., 2000)

${ }^{2}$ M. S. Feng, C. W. Liang, D. Tseng, J. Electrochem. Soc. 141, 1040 (1994).

${ }^{3}$ C. S. McCorrnick, C. E. Weber, J. R. Abelson, J.Vac.Sci.Technol.A 15(5), 2770 (1997).

${ }^{4}$ S. M. Gates, Mater. Res. Soc. Symp. Proc. 467, 843 (1997).

${ }^{5}$ H. Gleskova, S. Wagner, Z. Suo, Mat. Res. Soc. Symp. Proc. 507 (1998).

${ }^{6}$ C.-S. Yang, L. L. Smith, C. B. Arthur, G. N. Parsons, J.Vac.Sci.Technol.B 18(2), 683 (2000).

${ }^{7}$ E. Vallat-Sauvain, U. Kroll, J. Meier, A. Shah, J. Pohl, J. Appl. Phys. 87, 3137 (2000).

${ }^{8}$ H. Matsumura, Jpn. J. Appl. Phys., Part 2 25, L949 (1986).

${ }^{9}$ P. Brogueira, J. P. Conde, S. Arekat, V. Chu, J. Appl. Phys. 78, 3776 (1995).

${ }^{10}$ A.H. Mahan, J. Carapella, B.P. Nelson, R.S. Crandall, I. Balberg, J. Appl. Phys. 69, 6728 (1991).

${ }^{11}$ J. Puigdollers, A. Orpella, D. Dosev, C. Voz, D. Peiró, J. Pallarés, L. F. Marsal, J. Bertomeu, J. Andreu, R. Alcubilla, Journal of Non-Crystalline Solids, 266-269, , 2000.

${ }^{12}$ P. Brogueira, V. Chu, A. C. Ferro, J. P. Conde, J.Vac.Sci.Technol.A 15(6), 2968 (1997).

${ }^{13}$ W. E. Spear, P. G. LeComber, Philos. Mag. 33, 935 (1976).

${ }^{14}$ G. Willeke, Amorphous \& Microcrystalline Sebmiconductor Devices, Vol. II, edited by Jerzy Kanicki, (Artech House, Inc., Norwood, MA, 1992) pp.55-88.

${ }^{15}$ H. N. Wanka, R. Zedlitz, M. Heintze, M. B. Schubert, $13^{\text {th }}$ European Photovoltaic Solar Energy Conference Proc., 1753 (H. S. Stephens \& Associates, Bedford, 1995).

${ }^{16}$ R. Brüggemann, A. Hierzenberger, P. Reinig, M. Rojahn, M. B. Schubert, S. Schweizer, H. N. Wanka, I. Zrinšcak, Journal of Non-Crystalline Solids 227-230, 982 (1998).

${ }^{17}$ A. R. Middya, J. Guillet, J. Perrin, J. E. Bourée, Mater. Res. Soc. Symp. Proc. 420, 289 (1996).

${ }^{18}$ R. O. Dusane, F. Diehl, U. Weber, B. Schroeder, Extended Abstract of $1^{\text {st }}$ Int. Conf. on Hot-Wire CVD Process, 173 (Kanazawa, 2000).

${ }^{19}$ P. Alpuim, V. Chu, J. P. Conde, J. Appl. Phys. 86, 3812 (1999).

${ }^{20}$ K. F. Feenstra, R. E. I. Schropp, W. F. Van der Weg, J. Appl. Phys. 85, 6843 (1999).

${ }^{21}$ W. B. Jackson, N. M. Amer, A. C. Boccara and D. Fournier, Appl. Opt. 20, 1333 (1981).

${ }^{22}$ M. Vanacek, J. Kocka, J. Strichlik, Z. Kosicek, O. Stika, A. Triska, Sol. Energy Mater 8, 411 (1983).

${ }^{23}$ N.Wyrsch, F.Finger,T.J.McMahon, M.Vanacek, J.Non-Cryst. Solids 137-138, 347 (1991).

${ }^{24}$ J. S. Lannin, Semiconductors and Semimetals, Part B 21 (Academic Press, New York, 1984). 
${ }^{25}$ T. Kaneko, M. Wakagi, K. Onisawa, T. Minemura, Appl. Phys. Lett 64, 1865 (1994).

${ }^{26}$ S. Veprek, F. A. Sarott, Z. Iqbal, Phys. Rev.B 36, 3344 (1987).

${ }^{27}$ R. A. Street, Hydrogenated Amorphous Silicon (Cambridge University Press, 1991).

${ }^{28}$ see for example, R. A. Street, Phys.Rev.B 43, 2454 (1991).

${ }^{29}$ R. A. Street, Phys.Rev.B 44, 10610 (1991).

${ }^{30}$ J. P. Conde, P. Brogueira, V. Chu, Philosophical Magazine B 76, No. 3, 299 (1997).

${ }^{31}$ J. I. Pankove, P. J. Zanzucchi, C. W. Magee, G. Lucovsky, Appl. Phys. Lett. 46, 421 (1985).

${ }^{32}$ P. St'ahel, P. Roca i Cabarrocas, P. Sladek, M. L. Theye, Mater. Res. Soc. Symp. Proc. 507, 649 (1998).

${ }^{33}$ N. M. Johnson, C. Herring, D. J. Chadi, Phys.Rev.Lett. 56, 769 (1986). 